How to Cite

Wido, A., Bajamal, A. H., Apriawan, T., Parenrengi, M. A., \& Al Fauzi, A. (2022). Deep vein thrombosis

prophylaxis use in traumatic brain injury patients in tropical climate. International Journal of Health \& Medical

Sciences, 5(1), 67-74. https://doi.org/10.21744/ijhms.v5n1.1840

\title{
Deep Vein Thrombosis Prophylaxis Use in Traumatic Brain Injury Patients in Tropical Climate
}

\author{
Akbar Wido \\ Department of Neurosurgery, Faculty of Medicine Universitas Airlangga - Dr. Soetomo Academic General \\ Hospital, Surabaya, Indonesia \\ Corresponding author email: wdo.ns.sby@gmail.com
}

\author{
Abdul Hafid Bajamal \\ Department of Neurosurgery, Faculty of Medicine Universitas Airlangga - Dr. Soetomo Academic General \\ Hospital, Surabaya, Indonesia \\ Email: hfbajamal@gmail.com \\ Tedy Apriawan \\ Department of Neurosurgery, Faculty of Medicine Universitas Airlangga - Dr. Soetomo Academic General \\ Hospital, Surabaya, Indonesia \\ Email: drtedyapri@fk.unair.ac.id

\section{Muhammad Arifin Parenrengi} \\ Department of Neurosurgery, Faculty of Medicine Universitas Airlangga - Dr. Soetomo Academic General \\ Hospital, Surabaya, Indonesia \\ Email: muhammad.arifin@fk.unair.ac.id
}

\author{
Asra Al Fauzi \\ Department of Neurosurgery, Faculty of Medicine Universitas Airlangga-Dr. Soetomo Academic General \\ Hospital, Surabaya, Indonesia \\ Email: aseaalfauzi@gmail.com
}

\begin{abstract}
Deep Vein Trombosis (DVT) is one of the extracranial complications after TBI. Prophylaxis DVT using on TBI reduce incidence and mortality. Climate variants of an area affect the risk of DVT. UV ray increasing synthesis of vitamin $D$ and lowering risk of thrombus fomation. A systematic review and meta-analysis we performed according PRISMA guidelines. A through literature search was conducted on PubMed, Scopus, and Cochrane database. Total 3 publications match study criteria with 178 samples, without 144 samples and 34 samples with prophylaxis. The overall incidence is $5 \%$ (0-6.8\%), without $6.25 \%$ (5.3-6.8\%) and with prophylaxis $0 \%$. No reported complications and $100 \%$ survival rate. The incidence of DVT in TBI in tropical climate is low on average $5 \%(0-$ $6.8 \%)$. There was no difference in the outcome of DVT in TBI in tropical climate which given and without DVT prophylaxis. Asian races ethnic protective factor and UV ray exposure may contributed to the low of incidence rate. Prevention of DVT is still recommended for the use of prophylaxis, mechanical compression and early mobilization in cases of TBI to prevent the occurrence of DVT.
\end{abstract}

Keywords---deep vein thrombosis, prophylaxis, TBI, traumatic, tropical climate

ISSN 2632-9433

Submitted: 27 November 2021 |Revised: 09 December 2021| Accepted: 15 January 2022 


\section{Introduction}

Traumatic brain injury is the leading cause of death (Winn, 2011). WHO predicts at 2030, brain injury will be the leading cause of disability and death worldwide. Complications that can occur after brain injury is deep vein thrombosis (DVT), it is a clots formation in the veins, especially in the lower extremities. DVT can be dangerously and deathly (Japanese, 2005). The incidence of DVT after trauma around 6\% - 58\% (Reiff et al., 2009). Climate variant is threat element of DVT, feasible mechanisms are climate-related hypersensitivity, haemostatic abnormalities and lack of activity during winter (Signorelli et al., 2017). Cold climate disturbing coagulation cascade and peripheral vasoconstriction, It makes vasoconstrictive tone of the arteries and veins, increasing risk of DVT. Tropical climate exposed to sunlight and UV makes increases vitamin D synthesis that is related to upregulation of thrombomodulin and downregulation of tissue factor (Signorelli et al., 2017; Sugden et al., 2008).

\section{Research Methods}

\section{Eligibility criteria}

Study used were fully accessible literature, clinical trials, prospective, retrospective, and observational cohorts on only English literature and the literature published less than 20 years who diagnosed with TBI in tropical region, and measured for whether have DVT or not. The DVT prophylaxis status recorded. Reviews, unpublished articles, letter to editor, abstracts, study not written in English were excluded from the study (Lensing et al., 1999; Kyrle \& Eichinger, 2005).

\section{Type of outcome measures}

Clinical outcome, measured with; Incidence of DVT, Morbidity after given prophylaxis DVT and Mortality.

\section{Search methods and identification of studies}

Information sources

The following databases were searched in July 2012 for primary studies: PubMed/Medline, Google scholar, Research Gate, and Cochrane. The limitations of the literature used are, literature only in English, literature published less than 20 years, fully accessible literature after filtering, and not case report literature or systematic review (Silver et al., 1996; van Schalkwyk et al., 2010).

\section{Search protocol}

Study question was formed from the PICO. Authors used the following search keywords to search all trials registers and databases: ("Traumatic Brain Injury" OR "TBI" OR "Traumatic Head Injury" OR "Brain Injury") AND ("Deep vein thrombosis" OR "DVT") AND ("DVT Prophylaxis" OR "Thrombosis Prophylaxis") (Jani \& Subagio, 2021; Komilova et al., 2021).

\section{Study selection and analysis}

Study were reviewed to identify clinical trials, prospective, retrospective, and observational cohorts with or without comparison groups reporting on the prophylaxis and non-prophylaxis of DVT in TBI patients. Three investigators (AW, AHB, TA) independently reviewed the study meeting our inclusion criteria; only literature in English, literature published less than 20 years, fully accessible literature, and literature with the following design: clinical trials, prospective, retrospective, and observational cohorts (Ghajar, 2000; Corrigan \& Hammond, 2013).

\section{Data extraction and management}

For eligible studies, three review authors (AW, AHB, TA) independently extracted data using the data extraction form on characteristics of patients and interventions, study quality, and outcomes of interventions (Higgins et al., 2019). For measured outcomes of (DVT incidence and DVT risk), we extracted the incidence of DVT in both of the experimental and control group (with its $95 \%$ confidence interval (CI) as reported by the study authors. We extracted 
the incidence of DVT in each group for pooled incidence risk analysis for DVT incidence. For DVT risk, dichotomous data of incidence in each arm for risk ratio outcome. Two review authors (AW, AM) entered all data into the Review Manager (RevMan) software version 5.4 (The Cochrane Collaboration, 2020).

Assessment of study quality and risk of bias in included studies

Review authors independently assessed risk of bias for each included study using the criteria outlined in the Cochrane Handbook for Systematic Reviews of Interventions for non-randomized studies, called as Risk of Bias in Nonrandomized Studies of Interventions (ROBINS-I) for non-randomized studies and Risk of Bias 2 (RoB 2) for randomized studies (Higgins et al., 2019). Any disagreement was resolved by discussion or by involving third assessor. We summarized judgements in 'Risk of bias' tables along with the characteristics of the included studies and interpreted the results of meta-analyses in light of the overall 'Risk of bias' assessment (Lo et al., 2014; Sterne et al., 2016).

\section{Measures of treatment effect}

We presented the results of the generic inverse variance data as pooled incidence rate with $95 \%$ confidence intervals (CI) for DVT incidence. For DVT risk, we presented the results of the dichotomous data as risk ratio with $95 \%$ confidence intervals (CI) to combine trials that measured the same outcome and same comparison. Meta-analysis was planned if the data were appropriate for pooling. Summary of estimates was presented as mean difference for the outcomes. Consequently, both fixed-effects and random-effects meta-analyses were used, although the latter was prespecified in the protocol. If pooling was inappropriate, a narrative synthesis was implemented. The definitions of CI, heterogeneity, and P value are conventional (CI 95\%; I2 <40\%: unimportant; 30\%-60\%: moderate; 50\%-90\%: substantial, 75\% - 100\%: considerable; P value <0.05: significant; P value for interaction <0.1: significant) (Higgins et al., 2019). Review Manager 5.4 was used for meta-analysis (The Cochrane Collaboration, 2020).

\section{Results and Discussion}

Search literature on journal databases boldly. The databases of bold journals used in the search include Medline/PubMed (12 journals), Google Scholar (333 journals), Research Gate (15 journals) and Cochrane (1 journal) with a total of 361 literatures obtained. After the duplication, obtained 99 duplications. Followed by a search for titles, abstracts and research locations obtained 14 filtered literature. Followed by full text, 11 literatures were excluded because 1 literature is a case report, 8 literatures does not describe tropical climate, 2 literatures not clear described incident rate. There were 3 literatures that met the criteria. The search process and result are presented in PRISMA flowchart in Figure 1. 


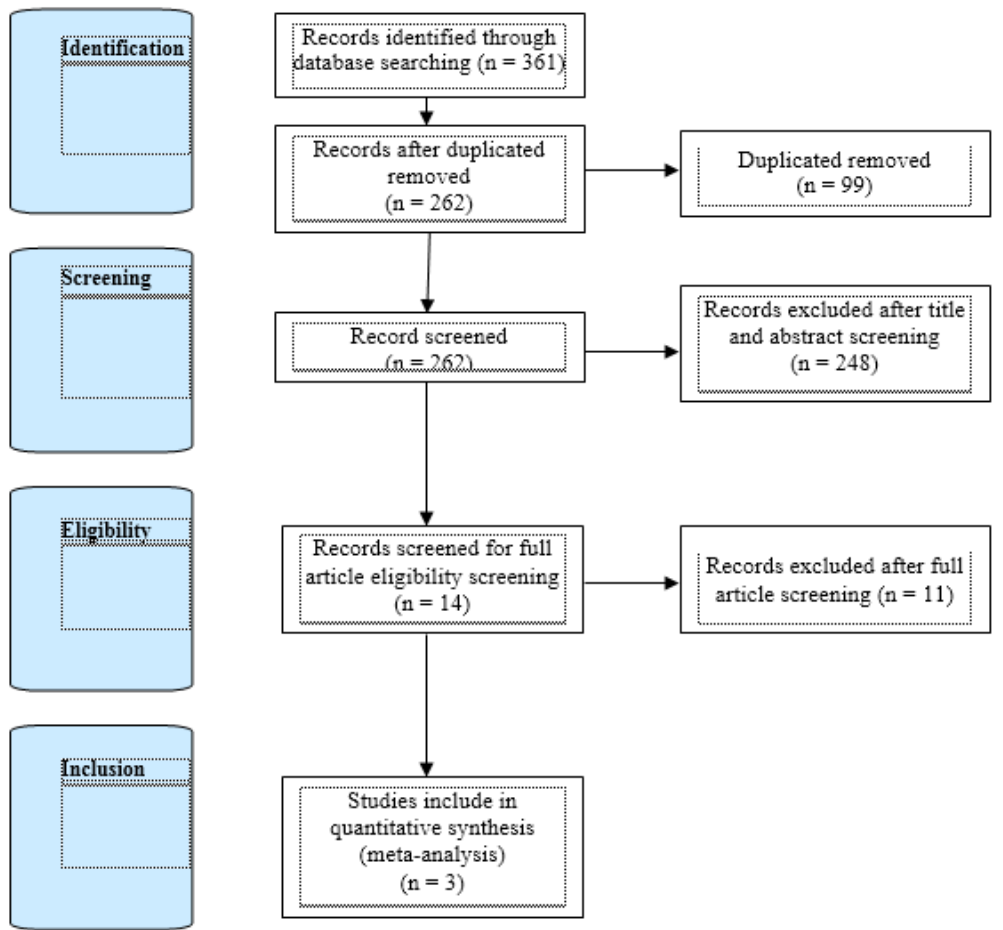

Figure 1. Preferred reporting items for systematic reviews and meta-analyses (PRISMA) guidelines flowchart

\section{Literature characteristics}

Three literatures meet inclusion criteria, shown in table 1. Existing literature was obtained from 2009 to 2016 . All literature was non-randomized clinical trial studies, a study without prophylaxis and two studies reporting prophylactic use. In general, there were a total of 178 TBI patients in this study with 9 patients experiencing DVT, $5 \%$ incidence rate.

Table 1

Characteristics of the literature included in the systematic review

\begin{tabular}{cclccc}
\hline No & Author & \multicolumn{1}{c}{ Title } & $\begin{array}{c}\text { Type of } \\
\text { Prophylaxis }\end{array}$ & $\begin{array}{c}\text { City or } \\
\text { Country }\end{array}$ & Climate \\
\hline 1 & Chua, 2009 & $\begin{array}{l}\text { Deep Venous Thrombosis in Asian Traumatic } \\
\text { Brain Injury Patients During Rehabilitation: } \\
\text { Prevalence and Risk Factors }\end{array}$ & without & Singapore & Tropic \\
2 & Behera et al., 2009 & $\begin{array}{l}\text { Incidence of Deep Vein Thrombosis in } \\
\text { Neurointensive Care Unit Patients-Does } \\
\text { Prophylaxis Modality Make Any Difference? } \\
\text { The incidence of deep venous thrombosis in } \\
\text { high-risk Indian neurosurgical patients: Need } \\
\text { for early chemoprophylaxis? }\end{array}$ & UFH & $\begin{array}{c}\text { Kernataka / } \\
\text { India }\end{array}$ & Tropic \\
George et al., 2016 & Tamil Ndu/ & Tropic \\
& & & India & \\
\hline
\end{tabular}

\section{Risk of bias analysis}

The result of bias risk assessment of studies involved measured by ROBINS-I for non-randomized studies. The result showed in Figure 2 and Figure 3 below. 


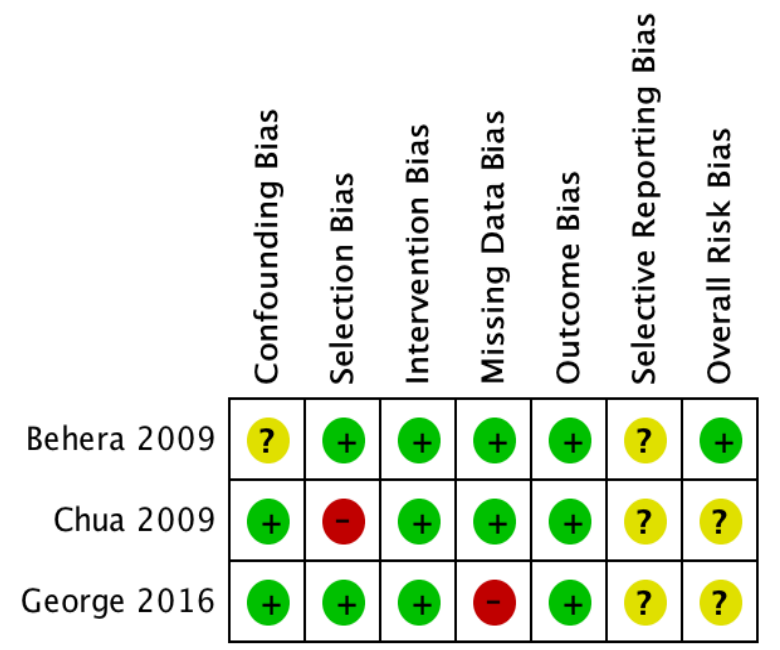

Figure 2. Risk assessment of bias using ROBINS-I for non-RCT studies

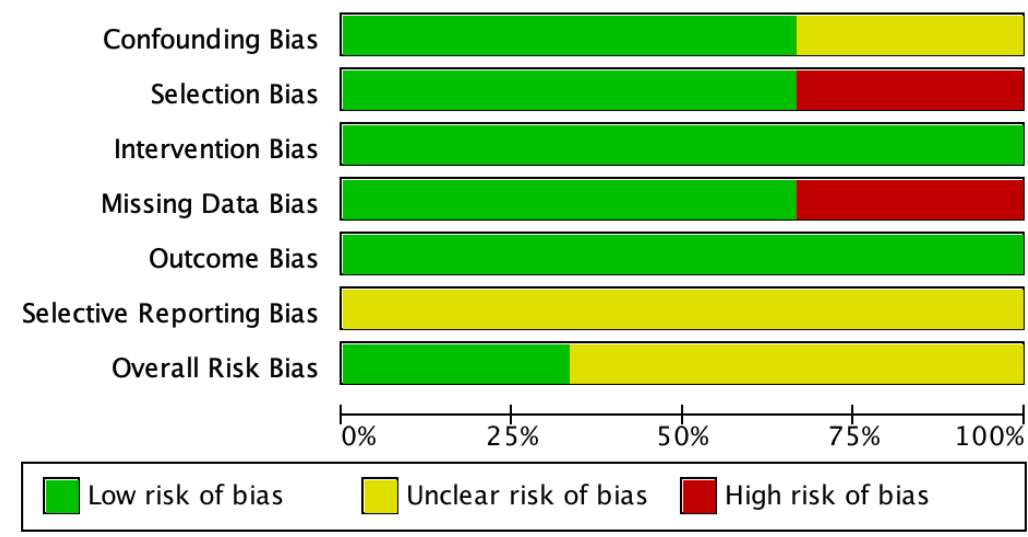

Figure 3. Proportion of the results of a risk assessment of bias using ROBINS-I for non-RCT studies based on an assessment for each risk of bias

DVT prophylaxis in TBI patients tropical climate

A journal reported group of patients using DVT prophylaxis shown in table 2 below.

Table 2

Characteristics of literature with DVT prophylaxis

\begin{tabular}{ccccccc}
\hline No & Author & $\begin{array}{c}\text { Number of } \\
\text { Sample }\end{array}$ & $\begin{array}{c}\text { Number of } \\
\text { DVT }\end{array}$ & $\begin{array}{c}\text { Incidence } \\
\text { rate }\end{array}$ & Complication & Survival rate \\
\hline 1 & $\begin{array}{c}\text { Behera et al., } \\
2009\end{array}$ & 34 & 0 & 0 & Mortality 0\% & $100 \%$ \\
& Total & 34 & 0 & 0 & & \\
\hline
\end{tabular}

A literature reported the incidence of DVT in patients given prophylaxis with incidence $0 \%$. The total number of patients obtained was 34 patients, with 0 patients experiencing DVT. Survival rates reported is $100 \%$ and no complication related given prophylaxis (Behera et al., 2019).

\section{Without DVT prophylaxis in TBI patients tropical climate}

Two literatures reports a group of TBI patients without DVT prophylaxis, shown in table 3 below. 
Table 3

Characteristics of the literature without DVT prophylaxis

\begin{tabular}{ccccccc}
\hline No & Author & $\begin{array}{c}\text { Number of } \\
\text { Sample }\end{array}$ & $\begin{array}{c}\text { Number of } \\
\text { DVT }\end{array}$ & Incidence rate & Complication & Survival rate \\
\hline 1 & Chua et al., 2009 & 56 & 3 & 5.3 & mortality 0\% & $100 \%$ \\
2 & George et al., 2016 & 88 & 6 & 6.8 & mortality 0\% & $100 \%$ \\
$\quad$ Total & 144 & 9 & 6.25 & & \\
\hline
\end{tabular}

Two literatures reported the incidence of DVT in patients without prophylaxis, the prevalence of $5.3-6.8 \%$. The total number of patients obtained was 144 patients, with 9 patients experiencing DVT. The crude incidence of DVT in this group of TBI patients without prophylaxis was 6.25\% (Chua et al., 2009; George et al., 2016). Two literatures reported survival rates and mortality, all survival rates is $100 \%$ and $0 \%$ mortality associated DVT (Chua et al., 2009; George et al., 2016; Wada et al., 2013). Forest plot pooled analysis of the incidence of DVT in patients without prophylaxis, found that DVT occurred in $6 \%$ of patients (95\% CI, 0.02-0.10) Between studies on this pooled analysis is homogenous $(\mathrm{I} 2=0 \%)$. The results of the analysis can be seen in forest plot (Figure 5) below.

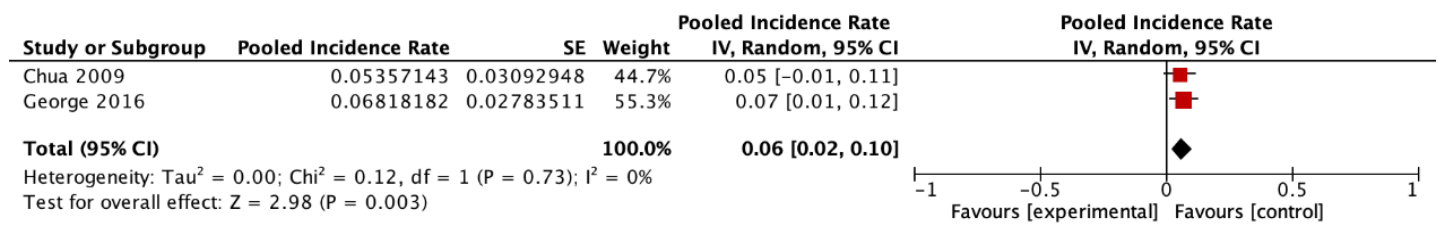

Figure 5. Pooled-analysis of the incidence of DVT in TBI patients not receiving prophylaxis in tropical

\section{Demographics}

The 3 literatures study resulted in a total of 178 patients, with 144 patients in the group without DVT prophylaxis and 34 patients in the group with DVT prophylaxis. A total of 9 patients had DVT in both groups, with 0 patient in the non-prophylactic group and 9 patients in the prophylactic group. The incidence rate of DVT in TBI patients in this study is $5 \%$. This figure is lower than the average incidence of DVT in major trauma patients 6-58\% and from cold climate 24-60\% (Japanese, 2005; Reiff et al., 2009).

\section{Confounding factors}

Therefore, there are several things that confound this situation. Study methodology from all literature is perspective observational, single center study, small sample size, loss follow up and diversity of time on admission (Behera et al., 2019; Chua et al., 2009; George et al., 2016).

\section{DVT prophylaxis in TBI patients tropical climate}

A literature discuss the use of DVT prophylaxis in TBI in tropical climate. The incidence rate is $0 \%$ and survival rate $100 \%$. Low incidence rate of DVT caused by small sample size, loss of followup and ethnic protective factor of Asia races. A literatur, single center and small sample size can't accurately discribed actual incidence rate of DVT (Behera et al., 2019).

\section{Without DVT prophylaxis in TBI patients tropical climate}

Two literatures reported TBI cases in TBI in tropical climate without given prophylaxis. The incidence rate ranged from $5.3 \%-6.8 \%$ with mean $6.25 \%$. The incidence rate is $6 \%$ from pooled analysis for incidence rate with homogenous sample (Pike, 1964; Hirunlabh et al., 1999). The incidence rate higher than incidence rate in the group with prophylaxis but lower than DVT in major trauma and cold climate. It can caused by post acute or rehabilitation phase admision which has passed from peak of hipercoagulation state. In areas with tropical climate get more UV rays from the sun every year, UV ray increase vitamin D synthesis, upregulation of thrombomodulin and downregulation tissue factor. It can reduce risk of obtained DVT. The protective effect of Asian races, majority of 
the study population, are known to have a lower propensity to develop DVT. High antithrombin, low protein C, and low protein S in Asian races are protective factors against DVT (Chua et al., 2009; George et al., 2016).

\section{Conclusion}

The incidence of DVT in TBI in tropical climate is low on average 5\% (0-6.8\%). There was no difference in the outcome of DVT in TBI in tropical climate which given and without DVT prophylaxis (Menon et al., 2010; Westgren \& Levi, 1998). Asian races ethnic protective factor and UV ray exposure contributed to the low of incidence rate. Prevention of DVT is still recommended for the use of prophylaxis, mechanical compression and early mobilization in cases of TBI to prevent the occurrence of DVT.

\section{Acknowledgments}

The author expresses his deep gratitude for all support and feedback. We also extend our gratitude to Neurosurgery Department and Medical Faculty of Airlangga universities. Without the help and support of all parties, this would not be possible.

\section{References}

Behera, S. S., Krishnakumar, M., \& Radhakrishnan Muthuchellappan, M. P. (2019). Incidence of Deep Vein Thrombosis in Neurointensive Care Unit Patients-Does Prophylaxis Modality Make Any Difference?. Indian journal of critical care medicine: peer-reviewed, official publication of Indian Society of Critical Care Medicine, 23(1), 43.

Chua, K. S., Kong, K. H., \& Arul, E. (2009). Deep venous thrombosis in Asian traumatic brain injury patients during rehabilitation: Prevalence and risk factors. The Journal of head trauma rehabilitation, 24(3), 178-186.

Corrigan, J. D., \& Hammond, F. M. (2013). Traumatic brain injury as a chronic health condition. Archives of physical medicine and rehabilitation, 94(6), 1199-1201. https://doi.org/10.1016/j.apmr.2013.01.023

George, A. J., Nair, S., Karthic, J. C., \& Joseph, M. (2016). The incidence of deep venous thrombosis in high-risk Indian neurosurgical patients: Need for early chemoprophylaxis?. Indian journal of critical care medicine: peerreviewed, official publication of Indian Society of Critical Care Medicine, 20(7), 412.

Ghajar, J. (2000). Traumatic brain injury. The Lancet, 356(9233), 923-929. https://doi.org/10.1016/S01406736(00)02689-1

Higgins, J. P., Thomas, J., Chandler, J., Cumpston, M., Li, T., Page, M. J., \& Welch, V. A. (Eds.). (2019). Cochrane handbook for systematic reviews of interventions. John Wiley \& Sons.

Hirunlabh, J., Kongduang, W., Namprakai, P., \& Khedari, J. (1999). Study of natural ventilation of houses by a metallic solar wall under tropical climate. Renewable Energy, 18(1), 109-119. https://doi.org/10.1016/S09601481(98)00783-6

Jani, J. R., \& Subagio, E. A. (2021). Managing the penetrated traumatic spinal injury by an airgun shot: A case report from Dr. Soetomo Hospital, Surabaya, Indonesia. International Journal of Health Sciences, 5(1), 46-52. https://doi.org/10.29332/ijhs.v5n1.1082

Japanese, C. S. (2005). Guidelines for the diagnosis, treatment and prevention of pulmonary thromboembolism and deep vein thrombosis (JCS 2004). Journal of cardiology, 45(3), 349.

Komilova, N. K., Rakhimova, T., Allaberdiev, R. K., Mirzaeva, G. S., \& Egamberdiyeva, U. T. (2021). Ecological situation: the role of education and spirituality in improving health of population. International Journal of Health Sciences, 5(3), 302-312. https://doi.org/10.53730/ijhs.v5n3.1512

Kyrle, P. A., \& Eichinger, S. (2005). Deep vein thrombosis. The Lancet, 365(9465), 1163-1174. https://doi.org/10.1016/S0140-6736(05)71880-8

Lensing, A. W., Prandoni, P., Prins, M. H., \& Büller, H. R. (1999). Deep-vein thrombosis. The Lancet, 353(9151), 479-485. https://doi.org/10.1016/S0140-6736(98)04298-6

Lo, C. K. L., Mertz, D., \& Loeb, M. (2014). Newcastle-Ottawa Scale: comparing reviewers' to authors' assessments. BMC medical research methodology, 14(1), 1-5.

Menon, D. K., Schwab, K., Wright, D. W., \& Maas, A. I. (2010). Position statement: definition of traumatic brain injury. Archives of physical medicine and rehabilitation, 91(11), 1637-1640. https://doi.org/10.1016/j.apmr.2010.05.017

Pike, J. G. (1964). The estimation of annual run-off from meteorological data in a tropical climate. Journal of Hydrology, 2(2), 116-123. https://doi.org/10.1016/0022-1694(64)90022-8 
Reiff, D. A., Haricharan, R. N., Bullington, N. M., Griffin, R. L., McGwin Jr, G., \& Rue III, L. W. (2009). Traumatic brain injury is associated with the development of deep vein thrombosis independent of pharmacological prophylaxis. Journal of Trauma and Acute Care Surgery, 66(5), 1436-1440.

Signorelli, S. S., Ferrante, M., Gaudio, A., \& Fiore, V. (2017). Deep vein thrombosis related to environment. Molecular medicine reports, 15(5), 3445-3448.

Silver, A., Eichorn, A., Kral, J., Pickett, G., Barie, P., Pryor, V., ... \& Antibiotic Prophylaxis Study Group. (1996). Timeliness and use of antibiotic prophylaxis in selected inpatient surgical procedures. The American journal of surgery, 171(6), 548-552. https://doi.org/10.1016/S0002-9610(96)00036-0

Sterne, J. A., Hernán, M. A., Reeves, B. C., Savović, J., Berkman, N. D., Viswanathan, M., ... \& Higgins, J. P. (2016). ROBINS-I: a tool for assessing risk of bias in non-randomised studies of interventions. $b m j, 355$.

Sugden, J. A., Davies, J. I., Witham, M. D., Morris, A. D., Struthers, A. D. (2008). Vitamin D improves endothelial function in patients with Type 2 diabetes mellitus and low vitamin D levels. Diabet. Med. 25, 320-325.

The Cochrane Collaboration. (2020). Review Manager (RevMan). Version 5.4.

van Schalkwyk, J., Van Eyk, N., Yudin, M. H., Boucher, M., Cormier, B., Gruslin, A., ... \& Wong, T. (2010). Antibiotic prophylaxis in obstetric procedures. Journal of Obstetrics and Gynaecology Canada, 32(9), 878-884. https://doi.org/10.1016/S1701-2163(16)34662-X

Wada, M., Iizuka, M., Iwadate, Y., Yamakami, I., Yoshinaga, K., \& Saeki, N. (2013). Effectiveness of deep vein thrombosis screening on admission to a rehabilitation hospital: a prospective study in 1043 consecutive patients. Thrombosis research, 131(6), 487-492.

Westgren, N., \& Levi, R. (1998). Quality of life and traumatic spinal cord injury. Archives of physical medicine and rehabilitation, 79(11), 1433-1439. https://doi.org/10.1016/S0003-9993(98)90240-4

Winn, H. R. (2011). Youmans Neurological Surgery E-Book. Elsevier Health Sciences. 